\title{
GPS: FERRAMENTA DE APOIO NA REALIZAÇÃO DE INVENTÁRIO FLORESTAL
}

\author{
Luciano Farinha Watzlawick ${ }^{1}$ \\ Carlos Roberto Sanquetta ${ }^{2}$ \\ Flávio Felipe Kirchner ${ }^{3}$
}

\begin{abstract}
RESUMO
O posicionamento e a instalação de unidades amostrais em trabalhos de Inventário Florestal exigem critérios (métodos e processos), que podem ser facilitados com o uso de recursos tecnológicos, saindo de uma esfera teórica para a prática. Neste sentido, o presente trabalho tem como finalidade apresentar um exemplo concreto de aplicação do Sistema de Posicionamento Global (GPS) para fornecer a posição geográfica (latitude e longitude) e a altitude do terreno em relação ao nível médio dos mares de parcelas amostrais em um inventário florestal. O processo de amostragem para o Inventário Florestal foi à amostragem sistemática em dois estágios. Concluiu-se que a utilização do GPS, como ferramenta de localização, navegação e apoio ao inventário florestal, proporcionou melhor rendimento, bem como uma economia de tempo e recursos na execução da atividade.
\end{abstract}

Palavras-chave: Amostragem, floresta de araucária, pinus.

\section{GPS: A HELPFUL TOOL IN FOREST INVENTORY}

\begin{abstract}
Positioning and establishing sample plots in forest inventories are tasks which require the definition of some criteria (methods and processes). This may be facilitated by using some technological devices that make the survey a very practical task. In this connection, this work aimed at presenting a clear example of application of Global Positioning System (GPS) used to give the geographical location (latitude and longitude) as well as the altitude of the land in relation to the medium level the seas of forest inventory sample plots. The sampling scheme used in the inventory was the double stage systematic process. It was noticed that GPS utilization, of location, sailing and as a tool to support forest inventory plot establishment, provides better efficiency in field work as well as improved time and resources use.
\end{abstract}

Keywords: Sampling, araucaria forest, pine

\footnotetext{
${ }^{1}$ Eng. Florestal, Msc. Prof. Departamento de Ciências Florestais, Universidade Federal do Paraná. Email: luciano farinha@uol.com.br

2 Eng. Florestal, Dr. Prof. Departamento de Ciências Florestais, Universidade Federal do Paraná. Email: $\underline{\text { sanqueta@ @loresta.ufpr.br }}$

${ }^{3}$ Eng. Florestal, Dr. Prof. Departamento de Ciências Florestais, Universidade Federal do Paraná. Email: kirchner@floresta.ufpr.br.

Recebido para publicação: 06/2001

Aceito para publicação: 05/2002
} 


\section{INTRODUÇÃO}

Com o desenvolvimento do GPS (Sistema de Posicionamento Global), pelo Departamento de Defesa e das Forças Armadas dos Estados Unidos, foi inventado um dos melhores auxílios à navegação e localização, e que possui um espectro de aplicações na ciência florestal, que devem ser exploradas e utilizadas de maneira mais prática, tornando os trabalhos de campo mais eficientes e com melhores rendimentos. Conforme Andrade et al. (1994), o GPS é muito importante no setor florestal, podendo-se realizar diversas operações, desde mapeamentos para fins de inventários florestais, navegação de aeronaves para identificação de áreas com doenças ou incêndios, facilitando o deslocamento, tornando-se assim mais ágil conhecer a posição geográfica, determinar velocidades de deslocamentos e gerar mapas destes deslocamentos.

Watzlawick et al. (2000) utilizaram o GPS na localização das unidades amostrais no Inventário Florestal Contínuo do Rio Grande do Sul, ressaltando-se a utilização desta tecnologia para localização de unidades amostrais e confecção de croquis haja vista sua praticidade e facilidade de operação dos aparelhos, sendo imprescindível para a realização de trabalhos de tal envergadura.

O intuito do presente trabalho é ilustrar como a tecnologia GPS pode ser empregada de maneira prática em um inventário florestal, em especial no tocante às possibilidades do uso do GPS de navegação na localização das unidades amostrais (parcelas).

\section{REVISÃO BIBLIOGRÁFICA}

\section{Considerações da utilização do gps sob coberturas florestais}

A utilização do GPS sob coberturas florestais diminui a força do sinal, afetando a sua performance. Gilbert (1997) salienta que esta diminuição afeta a quantidade (capacidade do receptor computar posições continuamente sob cobertura florestal) e a precisão (repetibilidade dessas posições ao longo do tempo). $\mathrm{O}$ autor ressalta ainda que outro aspecto que influi é a densidade de cobertura florestal, a qual pode ser medida em termos de porcentagem do céu que está obstruído pelas árvores. Cita por exemplo que em florestas naturais mais densas, muitas vezes o sinal pode não penetrar, ao contrário dos reflorestamentos, onde o sinal pode freqüentemente ser recebido com relativo sucesso.

Com relação ao tamanho dos galhos, aqueles de pequeno diâmetro próximos à antena podem ocasionar maior obstrução do que outros de maior diâmetro, porém mais distantes. De forma geral, quanto maior a densidade da cobertura, pior será a recepção do sinal do GPS.

Gilbert (1997), salienta que árvores que possuem um alto conteúdo de água nas folhas ocorre o processo de atenuação dos sinais de GPS, acarretando maiores problemas de recepção do que naquelas que possuem menor conteúdo. Árvores carregadas de água ou gelo certamente atenuam mais os sinais do GPS do que quando secas.

A forma da cobertura pode afetar a precisão do sinal, agindo como uma barreira física que reflete os sinais de maneira complexa. Estes sinais refletidos são conhecidos como processo de multicaminhamento (a antena recebe uma combinação de sinal, sinal direto e sinal refletido, resultando em pouca precisão). Outro problema está relacionado ao deslocamento, pois quando se trabalha sob cobertura florestal, quando os sinais muitas vezes podem sofrer interrupção e re-aquisição, agravando o problema pelo movimento rápido no interior da floresta.

Watzlawick et al. (2000), com relação a utilização do GPS de navegação na localização das unidades amostrais do Inventário Florestal Contínuo do Rio Grande do Sul, afirmam que o mesmo prestou-se para a realização dos trabalhos. Os autores salientam também a importância na confecção de croquis, os quais serão úteis e facilitarão o retorno das equipes de medição nas próximas etapas de realização do mesmo, acarretando assim uma economia de tempo e recursos financeiros.

Prodan et al. (1997), ao comentar sobre a utilização de receptores GPS, afirmam que além de fornecer informações em tempo real, estes podem armazenar na memória grande quantidade de dados (coordenadas, 
atributos de pontos notáveis, rotas...). Assim, o uso desta ferramenta permite traçar itinerários de navegação, estabelecendo assim o máximo de precisão em uma serie de medidas. Os autores ainda comentam quanto ao uso deste tipo de aparelho na atividade florestal em especial nos trabalhos de medições e inventários florestais.

Divis (2000), comenta a precisão dos receptores GPS com relação ao desligamento da SA (disponibilidade seletiva), para receptores com código dez $-\mathrm{n}<25$ metros em $95 \%$, e para os receptores geodésicos dez $-\mathrm{n}<$ 10 metros em $95 \%$.

Drago e Disperati (1996), salientam que a utilização do GPS na engenharia florestal possui diversas aplicações nas mais diversas atividades. Porém, o uso é limitado pela presença de vegetação densa e outros obstáculos físicos que impedem a captura dos sinais emitidos pelo satélite. Os principais usos para atividades florestais são: orientação de equipes de campo em florestas; determinar pontos que definam as unidades amostrais, necessárias em inventários florestais; definir limites de diferentes formações florestais, dentre muitas outras aplicações em manejo florestal, silvicultura e conservação dos recursos naturais.

\section{Estudo de caso}

Uso do GPS de Navegação em Inventário Florestal

Localização e caracterização da área de estudo

A área de estudo está localizada entre as coordenadas $26^{\circ} 20^{\prime} 35^{\prime}$ ' $\mathrm{S}$ e $26^{\circ} 26^{\prime} 13^{\prime \prime} \mathrm{S}$, e $51^{\circ} 19^{\prime} 49^{\prime \prime} \mathrm{W}$ e $51^{\circ} 25^{\prime} 29^{\prime}$ 'W, na Região Sul do Paraná, no município de General Carneiro. O levantamento dos dados de Inventário florestal foi realizado em uma área de 4.211 ha conforme Pizzatto (1998), nas fazendas São Pedro I, São Pedro II e Santa Cândida, de propriedade das Indústrias Pedro N. Pizzatto Ltda.

Pela classificação climática de Koeppen, o clima da região é caracterizado como Subtropical Úmido Mesotérmico $(\mathrm{Cfb})$, sem estação seca, com verões frescos e invernos com ocorrência de geadas severas. A médias das temperaturas dos meses mais quentes é inferior a $22^{\circ} \mathrm{C}$ e a dos meses mais frios é superior a $18^{\circ} \mathrm{C}$ (PARANÁ, 1987).
Nesta região, ocorrem solos orgânicos e hidromórficos, com predomínio de solos Litólicos e Cambissolos (Paraná, 1987; Castela et al., 2001). Ocorrem também associações com podzólicos e latossólicos e solos orgânicos e Terra Bruna Estruturada (Castela et al., 2001).

O mesmo autor relata que a vegetação natural encontrada corresponde ao bioma da Floresta Ombrófila Mista ou Floresta com Araucária. Para Leite (1994), poucas são as formações florestais brasileiras que têm sua fisionomia tão bem caracterizada pela presença de uma espécie vegetal. Acrescenta ainda que mesmo com a profunda alteração a que foi submetida a cobertura vegetal do Estado do Paraná, a presença de remanescentes de araucária, mesmo que isolados, atesta a distribuição do bioma e facilita grandemente sua definição.

Em trabalhos desenvolvidos por Sanquetta (1998), a área apresenta uma diversidade biológica expressiva, pelas distintas situações de histórico de manejo, pelas diferenças edáficas e microclimáticas. Entretanto, pode-se generalizar que a araucária predomina no dossel. Porém, ocorrem áreas onde o domínio é da imbuia (Ocotea porosa) ou sapopema (Sloanea lasiocoma). Nos estratos inferiores, dentre as várias espécies que ocorrem, destacam-se as do gênero Nectandra, Ocotea, Ilex paraguariensis, Prunus brasiliensis, Lithraea brasiliensis, Sapium glandulatum, Clethra scabra, Jacaranda puberula e diversas Mirtáceas, dentre muitas outras espécies.

\section{MATERIAIS E MÉTODOS}

O processo de amostragem utilizado para o Inventário Florestal foi o sistemático em dois estágios. Conforme Péllico-Netto e BRENA (1997), neste processo as unidades amostrais são selecionadas através de duas etapas ou fases de amostragem, cada uma delas com um intervalo em espaço. Os autores complementam recomendando este processo de amostragem para populações extensas e de difícil acesso e para populações em que não se disponha de mapas da área florestal a ser inventariada.

A área de trabalho possui mapas temáticos de uso da terra em escala 1:10.000, 
com os seguintes temas vegetacionais de interesse: floresta primária, floresta secundária, capoeirão, reflorestamento de Pinus taeda e reflorestamento de Araucaria angustifolia.

Sobre estes mapas, os quais encontram-se referenciados a um sistema de coordenadas UTM (m), distribuiu-se uma rede sistemática de $550 \mathrm{~m}$ x $550 \mathrm{~m}$, definindo-se os pontos das unidades amostrais. Na intersecção destes pontos potenciais determinaram-se as coordenadas, as quais estavam condicionadas à existência de vegetação para realização do levantamento de campo.

Esses pontos foram transferidos e marcados no mapa temático, selecionando-se assim as unidades amostrais onde $\mathrm{o}$ levantamento de campo seria realizado. Cada unidade amostral marcada recebeu uma numeração própria e suas coordenadas UTM.

O GPS utilizado foi o de navegação, modelo GARMIM 12GL, o qual segundo o fabricante possui uma precisão planimetríca em torno de 5 a 15 metros. Além dos mapas temáticos, foram utilizados materiais auxiliares para anotações e medições florestais.

Ressalta-se que o mapa temático, além dos temas de vegetação, possuía ainda marcação de estradas, caminhos, rede de drenagem, áreas de preservação permanente, bem como toponímia de pontos notáveis no terreno (torres, pontes, etc.).
As unidades amostrais foram locadas por meio de coordenadas UTM, as quais eram inseridas no GPS, com a respectiva identificação do número da unidade amostral. Com o mapa de apoio, bem como informações prestadas por pessoas que conhecem as estradas, realizava-se um estudo buscando sempre o menor e o melhor itinerário a ser seguido, para a correta localização da mesma. $\mathrm{O}$ posicionamento e a instalação da unidade amostral, foi realizada com a materialização de seus limites utilizando canos de PVC como piquetes.

\section{RESULTADOS E DISCUSSÃO}

A utilização do GPS em trabalhos de inventários florestais, tanto em florestas nativas como em reflorestamentos possui algumas implicações, devido a alguns destes ambientes apresentarem uma cobertura de copas muito densa, ou por possuírem uma grande densidade de plantas por hectare. A desativação da parte técnica de segurança SA melhorou a qualidade do posicionamento.

Como causadores destas variabilidades têm-se o efeito do multicaminhamento (Figura 1), sendo este resultado da interferência entre a recepção dos sinais diretos e indiretos (refletidos), acarretando em atrasos do sinal.

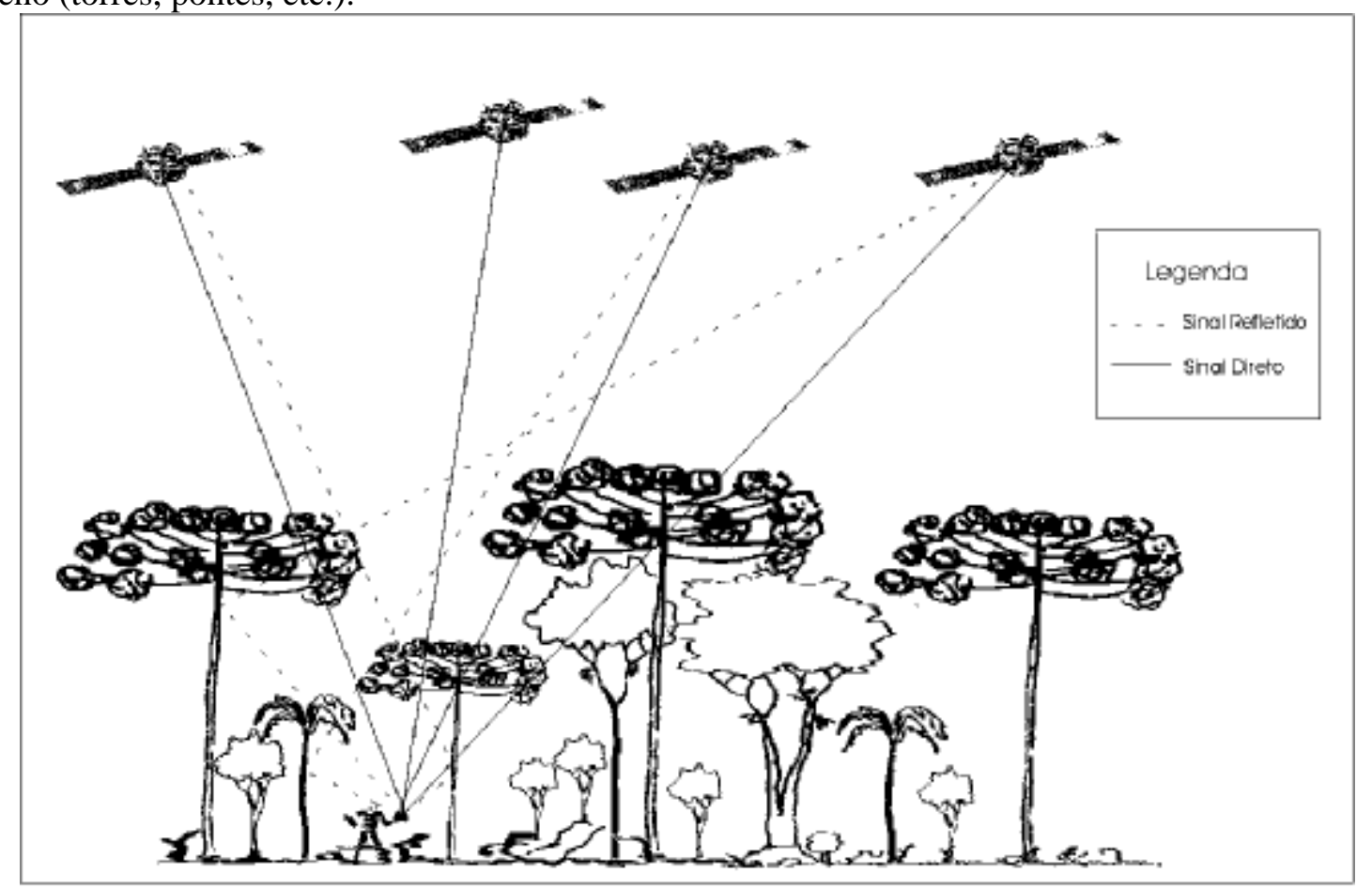

Figura 1: Efeito do multicaminhamento em um ambiente florestal. 
O outro efeito, chamado de perda de sinais (Perda de Ciclos), é conseqüência da constante interrupção e reaquisição dos sinais pela presença de obstáculos como árvores, galhos, ou devido a baixa elevação dos satélites, que conforme GILBERT (1997), a elevação dos satélites é um dos fatores que pode afetar a precisão do GPS. O mesmo autor relata que sinais obtidos por satélites que estão a menos de $15^{\circ}$ acima do horizonte estão sujeitos a propagação de erros maiores do que aqueles que se encontram em maior altitude, devido ao efeito da troposfera sobre o sinal, para minimizar este erro é introduzido nos receptores uma máscara de $15^{\circ}$. Este erro de posicionamento é conhecido como parâmetro cut-off-angle, sendo representado na Figura 2.

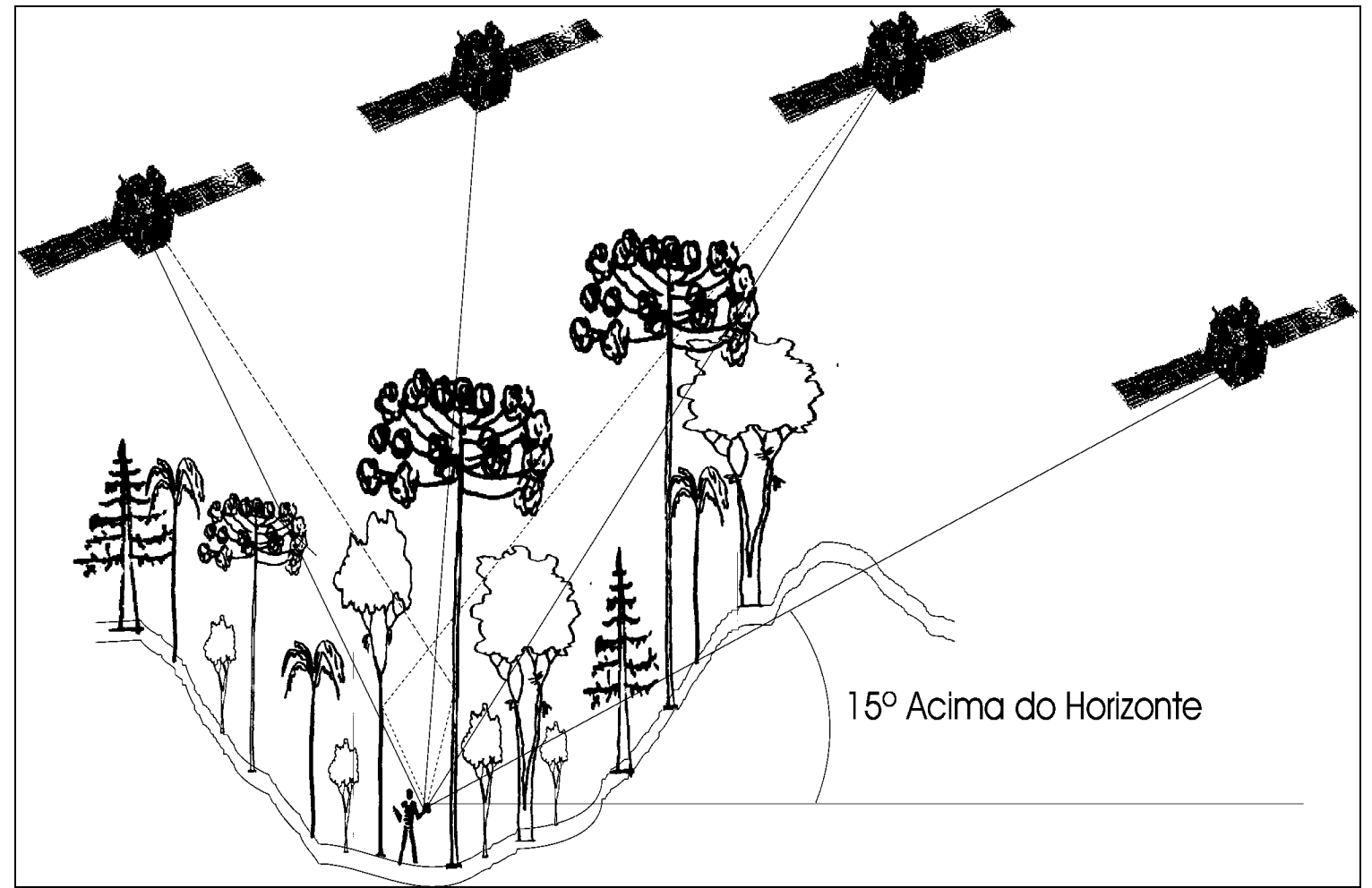

Figura 2: Efeito do parâmetro cut-off-angle em ambiente florestal.

Como no presente trabalho teve-se como objetivos, verificar a viabilidade da utilização e o comportamento do GPS nos diferentes ambientes florestais (floresta nativa e reflorestamentos), os quais estavam sendo inventariados. Para fins de melhor interpretação e utilização desta ferramenta, os resultados nestes ambientes serão apresentados separadamente.

No ambiente da floresta primária, o receptor GPS apresentou um comportamento bastante irregular, quando se encontrava próximo ás árvores que possuem grande diâmetro, ou em locais em que o dossel apresentava-se bastante fechado, mesmo assim foi possível localizar os pontos amostrais, sendo necessário neste ambiente, muitas vezes, deslocar-se com maior rapidez para evitar as perdas de sinais pelo exposto acima.

Em floresta secundária, as quais apresentam uma cobertura de copas bem menor, também apresentando clareiras em seu interior, houve uma melhor recepção dos sinais, ocorrendo perdas de sinal apenas quando a floresta apresentava um sub bosque muito denso, impedindo assim a recepções de sinais.

No ambiente denominado de capoeirão, o qual apresenta uma grande densidade de plantas, e ao contrário das florestas primárias, as quais possuem galhos mais grossos e altos, o capoeirão possui uma grande densidade de galhos finos e baixos, estando os mesmos próximos ao receptor GPS, ocasionando assim perdas de sinal, 
confirmando a afirmação de GILBERT (1997), "galhos de menor diâmetro podem ocasionar maior obstrução quando pertos do receptor que os galhos mais grossos, porém distantes do aparelho receptor".

Em reflorestamentos, tanto de Pinus taeda como de Araucaria angustifolia não ocorreram problemas quanto à recepção de sinal, talvez devido a ter sido realizado desbaste nos mesmos, apresentando assim uma menor densidade de plantas por hectare, bem como uma menor área de cobertura das copas.

\section{CONCLUSÃO E RECOMENDAÇÃO}

A partir dos resultados obtidos, podese concluir da importância da aplicação desta ferramenta em inventários florestais, apesar de se constatar algumas restrições quanto da sua utilização em ambientes florestais que possuam uma cobertura de copas muito fechada, bem como quando apresentar um grande número de galhos muito próximos ao receptor GPS, ou árvores com grandes diâmetros; os quais provocam erros.

Conclui-se também que com a utilização do GPS, a localização das unidades amostrais se dá em um tempo bem menor. Conseqüentemente com menores custos, além de possuir a possibilidade de inserção da unidade amostral em um ambiente SIG (Sistema de Informação Geográfica).

Com a inserção das unidades amostrais em ambiente SIG, obtém-se um aprimoramento, melhor visualização e a maior agilização nos processos de tomada de decisões, de maneira integrada com os demais planos de informação constantes no ambiente. Este também permite associar todas as informações a um banco de dados relacional, com facilidade para acesso às informações cadastrais, facilitando assim os processos de tomada de decisões.

Recomenda-se testar a utilização do GPS nos mais variados ambientes florestais nativos, bem como em reflorestamentos com os mais variados tipos de intervenções. Para evitar os efeitos de multicaminhamento e da perda de sinal em função da cobertura florestal, sempre utilizar antenas que ultrapassem o dossel, através da elevação da mesma acima do dossel. Já para os efeitos do parâmetro cut-off-angle, sempre inserir uma máscara igual a $15^{\circ}$.

\section{BIBLIOGRAFIA CITADA}

ANDRADE, J. B. de; ANDRADE, R. do R. de; SOUTO, R. B.; ZUNINO, L. A. A Importância do GPS no mapeamento florestal. In: I SEMINÁRIO DE ATUALIZAÇÃO EM SENSORIAMENTO REMOTO E SISTEMAS DE INFORMAÇÕES GEOGRÁFICAS APLICADOS À ENGENHARIA FLORESTAL. Curitiba, 1994, Anais..., p. 41 48.

CASTELA, P.R.; BRITEZ, R.M.; TIEPOLO, G.; PIRES, L.A. Conservação do bioma floresta com araucária. Relatório final: Diagnóstico dos remanescentes florestais, v.1/2. PROBIO-MMA/BANCO MUNDIAL/GEF/CNPq/FUPEF. 2001. 456p.

DRAGO, D.; DISPERATI, A. A. Aspectos básicos sobre GPS. Série Didática, FUPEF, Curitiba, n. 6. 17p. 1996.

DIVIS, D. A. SA: Going the way of the dinosaur. GPS World, Washington, p.16-19, june. 2000.

GILBERT, C. Performance sob coberturas Florestais. Fator GIS, Curitiba, v. 5, n. 18, p. 52-53, março/abril. 1997.

GILBERT, C. Erros em GPS. Fator GIS, Curitiba, v. 5, n. 19, p. 62-63, maio/junho. 1997.

LEITE, P. F. As diferentes unidades fitoecológicas da região sul do Brasil proposta de classificação. Curitiba, 1994. Dissertação (Mestrado em Engenharia Florestal) - Setor de Ciências Agrárias, Universidade Federal do Paraná.

PARANÁ. Atlas do Estado do Paraná. Secretária de Estado de Agricultura e Abastecimento, Instituto de Terras, cartografia e florestas, 1987. 73p.

PÉlLICO NETO, S.; BRENA, D. A. Inventário florestal. Curitiba: Editorado pelos autores. 1997, 316 p.

PIZZATTO, L. Relatório de Execução de Planos de Manejo Florestal - Informações até Dez/97. Indústrias Pedro N. Pizzatto., 1998. Relatório técnico. 
GPS: Ferramenta de Apoio na Realização...

PRODAN, M.; PETERS, R.; COX, F.; REAL, P. Mensura forestal. San José, C.R. : Deutsche Gesellschaft für Techische Zusammenarbeit (GTZ) Cmbh: Instituto Interamericano de Cooperación para la Agricultura (IICA), 1997, 586p.

SANQUETTA, C. R. Inventário Contínuo em Floresta Natural - implantação de um sistema de monitoramento de crescimento e produção. Indústrias Pedro N. Pizzatto/FUPEF, 1998. (Relatório de Pesquisa)

WATZLAWICK, L. F.; BRENA, D. A.; MADRUGA, P. R. de A. BOLFE, E. L.; PEREIRA, M. N. Utilização de GPS na localização das unidades amostrais no Inventário Florestal Contínuo do Rio Grande do Sul. In: VIII CONGRESSO FLORESTAL ESTADUAL DO RIO GRANDE DO SUL. Nova Prata, 2000, Anais ... (no prelo)

\section{AGRADECIMENTOS}

Os autores agradecem aos Diretores e Funcionários das Indústrias Pedro N. Pizzatto Ltda., pelo apoio e suporte ao desenvolvimento deste trabalho. Agradecimentos também são dados aos diversos acadêmicos do Curso de Engenharia Florestal da UFPR, que participaram nos trabalhos de campo. 